\title{
Kinetic Studies on the Conversion of Levoglucosan to Glucose in Water Using Brønsted Acids as the Catalysts
}

\author{
R. M. Abdilla, ${ }^{\dagger+\hbar}$ C. B. Rasrendra, ${ }^{\S}$ and H. J. Heeres* ${ }^{* \dagger \odot}$ \\ ${ }^{\dagger}$ Green Chemical Reaction Engineering, University of Groningen, Nijenborgh 4, 9747 AG Groningen, The Netherlands \\ ${ }^{\ddagger}$ Department of Chemical Engineering, University of Brawijaya, MT. Haryono 167, Malang 65145, Indonesia \\ ${ }^{\S}$ Department of Chemical Engineering, Institut Teknologi Bandung, Ganesha 10, Bandung 40132, Indonesia
}

\section{Supporting Information}

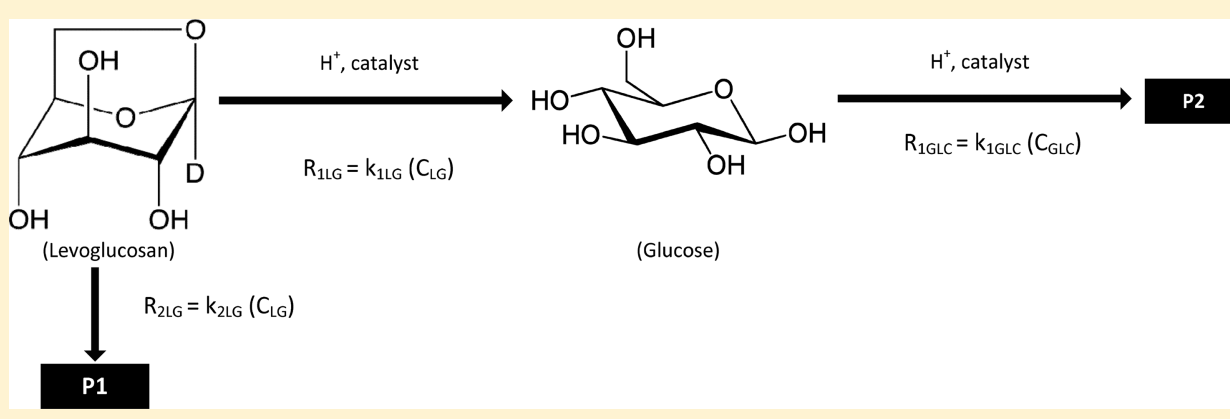

ABSTRACT: Fast pyrolysis is as a promising and versatile technology to depolymerize and concentrate sugars from lignocellulosic biomass. The pyrolysis liquids produced contain considerable amounts of levoglucosan (1,6-anhydro- $\beta$-Dglucopyranose), which is an interesting source for glucose (GLC). Here, we report a kinetic study on the conversion of levoglucosan (LG) to GLC in water using sulfuric and acetic acid as the catalysts under a wide range of conditions in a batch setup. The effects of the initial LG loading $(0.1-1 \mathrm{M})$, sulfuric and acetic acid concentrations (0.05-0.5 M and $0.5-1 \mathrm{M}$, respectively), and reaction temperatures $\left(80-200{ }^{\circ} \mathrm{C}\right)$ were determined. Highest GLC yields were obtained using sulfuric acid (98 mol \%), whereas the yields were lower for acetic acid (maximum $90 \mathrm{~mol} \%$ ) due to the formation of byproducts such as insoluble polymers (humins). The experimental data were modeled using MATLAB software, and relevant kinetic parameters were determined. Good agreement between experimental and model was obtained when assuming that the reaction is first order with respect to LG. The activation energies were $123.4 \mathrm{~kJ} \mathrm{~mol}^{-1}$ and $120.9 \mathrm{~kJ} \mathrm{~mol}^{-1}$ for sulfuric and acetic acid, respectively.

\section{INTRODUCTION}

Biomass is considered the only sustainable carbon source for the production of carbon-based fuels and chemicals with low carbon emissions. ${ }^{1-3}$ A particularly interesting biomass source is lignocellulose biomass, the most abundant and renewable form of biomass on earth. ${ }^{4}$ Particularly the cellulose and hemicellulose fraction in lignocellulosic biomass may be used as a renewable source for biofuels and biobased chemicals by catalytic conversions, often after an initial pretreatment to obtain monomeric sugars. ${ }^{4,5}$

A promising and versatile technology for the pretreatment of lignocellulosic biomass is fast pyrolysis. ${ }^{6-8}$ Fast pyrolysis is an alternate method to acid and enzymatic hydrolysis of lignocellulosic biomass to obtain (monomeric) sugars from biomass. ${ }^{9}$ In fast pyrolysis processes, lignocellulosic biomass (e.g, forestry residue) is rapidly heated (typically, $<2$ s, 450$600{ }^{\circ} \mathrm{C}$ ), in the absence of oxygen under atmospheric pressure. $^{10-13}$ The vapors formed are rapidly cooled into a liquid product known as pyrolysis liquids (bio-oils). Typical liquid yields are reported to be up to $75-85$ wt $\%$ of the initial biomass feed. ${ }^{5,6,13}$ Generally, pyrolysis liquids are complex mixtures of numerous oxygenated compounds of various organic groups such as carboxylic acids, alcohols, ketones, aldehydes, phenolics, and sugars. ${ }^{14}$ Compared to other biomass conversion technologies, pyrolysis offers a number of advantages such as (i) low capital investment and operating $\operatorname{costs}^{15}$ (ii) the possibility to use a wide variety of biomass feeds, including agricultural wastes, grasses, and woody biomass, ${ }^{16-18}$ and (iii) pyrolysis is a fast process compared to biological approaches. ${ }^{17,19}$

Levoglucosan (1,6-anhydro- $\beta$-D-glucopyranose) is known to be among the major products found in pyrolysis oil and is actually the primary degradation product of cellulose., ${ }^{5,9}$ The yield of levoglucosan (LG) in pyrolysis oil varies and is dependent among others on the type of feedstock and the operating conditions. LG yields of up to $33 \mathrm{wt} \%$ have been reported when using cotton as the biomass feed. ${ }^{20}$ When pure cellulose is used as the starting material, the yield can be as high as $60 \mathrm{wt} \%{ }^{7,21} \mathrm{LG}$ is an example of an anhydrosugars, and it is

Received: January 3, 2018

Revised: February 9, 2018

Accepted: February 14, 2018

Published: February 14, 2018 


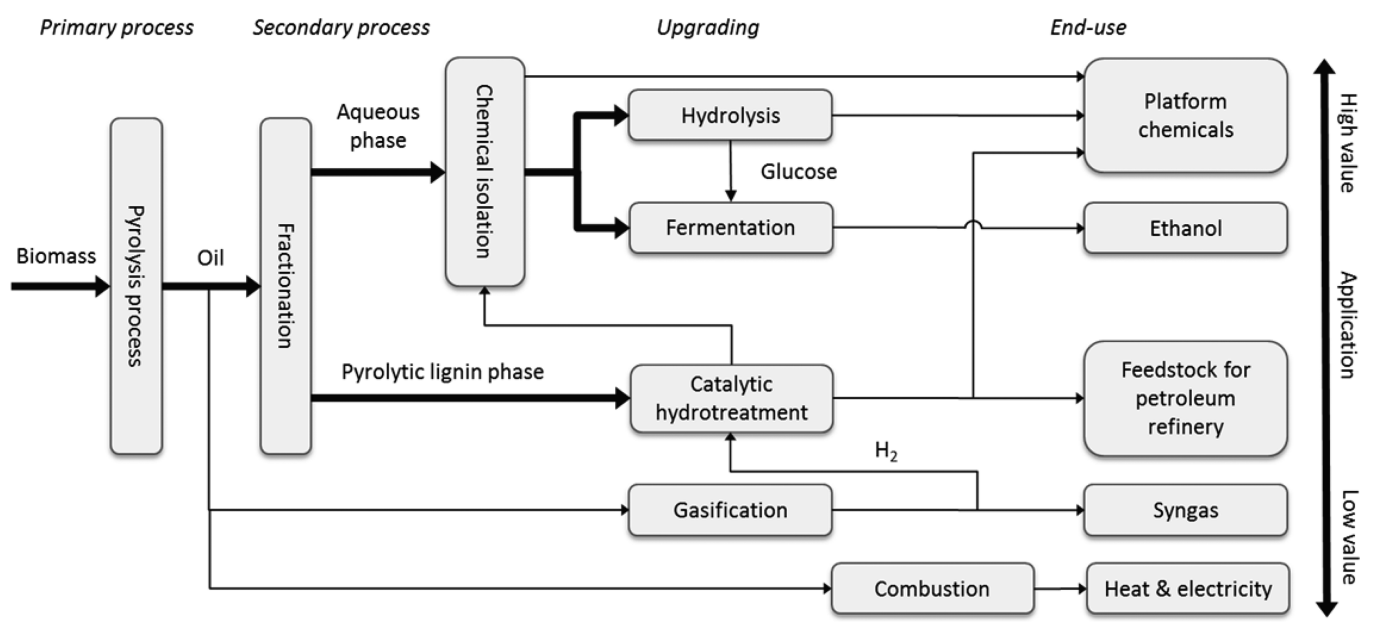

Figure 1. Biorefinery concept for pyrolysis technology (Reprinted with permission from ref 28. Copyright 2014 RSC).

readily converted to glucose (GLC) by an acid-catalyzed hydrolysis. ${ }^{5}$ GLC is a known precursor for biofuels (bioethanol) and biobased chemicals. Examples of the latter are 5-hydroxymethylfurfural (HMF), levulinic acid (LA), and lactic acid (LAC), which are versatile platform chemicals and precursor for biodegradable polymers. ${ }^{22}$ As such, isolation and valorization of the sugar fraction and particularly LG from pyrolysis liquids could improve the techno-economic feasibility of the pyrolysis process (Figure 1). Various approaches have been identified to separate the sugar fraction in the pyrolysis liquid from the pyrolytic lignin fraction, of which liquid-liquid extraction combined with destillative workup is considered the most promising. ${ }^{5,23-25}$ It allows isolation of the sugar fraction as a liquid in good yields (up to $34 \mathrm{wt} \%$ of the original oil). ${ }^{26}$ The composition has been determined in detail, and it typically consists of LG (16 wt \%), glycoaldehyde (11 wt \%), acids (2.5 wt \%), ketones (1.4 wt \%), and phenolics $(0.4 \mathrm{wt} \%){ }^{27}$

For the development of technology to convert the sugar fraction of pyrolysis liquids monomeric sugars to be used for further conversions, it is essential to gain insights into the rate of hydrolysis reactions. We here report a kinetic modeling study on the conversion of LG to glucose. To the best of our knowledge, a limited number of kinetic studies have been reported for this reaction. LG hydrolysis in water with hydrochloric acid catalyst was investigated by Vidrio in $2004 .^{29}$ The reactions were carried out at low temperature $\left(25-50{ }^{\circ} \mathrm{C}\right)$ over a six-week period. The activation energy found in this study was $97 \mathrm{~kJ} \mathrm{~mol}^{-1}$. Helle et al. ${ }^{9}$ studied the reaction of LG in water, spent sulfite liquor, and/or pyrolysis oil extract using sulfuric acid as the catalyst in a temperature range between 50 and $130{ }^{\circ} \mathrm{C}$. Activation energies of $114 \mathrm{~kJ} \mathrm{~mol}^{-1}$ and $87 \mathrm{~kJ} \mathrm{~mol}^{-1}$ were found for the hydrolysis of LG in dilute sulfuric acid and in spent sulfite liquor or pyrolysis oil extract, respectively. In both studies, first order kinetics were assumed, and the effects of the initial concentration of LG on reaction kinetics were not determined.

We here report an experimental and modeling study on the conversion of LG to GLC under acidic conditions in aqueous solutions. Sulfuric acid and acetic acid were selected as the catalysts using a broad range of reaction conditions. Acetic acid was selected as it is abundantly available in pyrolysis liquids with concentrations up to $10 \mathrm{wt} \%{ }^{30}$ The effects of reaction parameters (acid concentration, temperature, initial LG loading) on the reaction rates were measured, and the relevant kinetic parameters were determined from the experimental data using MATLAB software. Differences between sulfuric acid and acetic acid will be highlighted, and the implications of the models regarding GLC yield will be discussed.

\section{EXPERIMENTAL SECTION}

2.1. Chemicals. LG was purchased from Carbosynth, UK. Sulfuric acid (96-98 wt \%) and GLC ( $\geq 99.5$ wt \%) were obtained from Sigma-Aldrich (Steinheim, Germany). Acetic acid (glacial) was acquired from Merk Milipore (Darmstadt, Germany). All chemicals were used without further purification. For all experiments, Milli-Q water was used to prepare the solutions.

2.2. Experimental Procedures. The experimental methods are based on published work by Girisuta et al. $(2006) .^{31}$ The hydrolysis reactions were carried out in glass ampules (i.d. $3 \mathrm{~mm}$, wall thickness of $1.5 \mathrm{~mm}$, and length of $15 \mathrm{~cm}$ ). The ampules were filled with approximately $0.3 \mathrm{~mL}$ of the reaction mixture consisting of a predetermined amount of LG (0.1-1 $\mathrm{M})$ and catalyst $(0.05-0.5 \mathrm{M}$ sulfuric acid, $0.5-1 \mathrm{M}$ acetic acid). After filling, the ampules were sealed with a torch. The ampules were placed in an aluminum rack and subsequently placed in a temperature-controlled oven (GC oven, HewlettPackard 5890A) at $T_{\text {oven }}=80-160{ }^{\circ} \mathrm{C}$ for experiments using sulfuric acid and at $T_{\text {oven }}=160-200{ }^{\circ} \mathrm{C}$ for experiments using acetic acid. At different reaction times, an ampule was removed from the oven and quickly quenched in cold water to stop the reaction. Typically, at least 8 ampules were used for one series of experiments. An overview of experimental data of all individual experiments is given in the Supporting Information. After reaction, the ampules were opened, and the reaction mixture was withdrawn. Subsequently, the mixture was filtered with $0.45 \mu \mathrm{m}$ PTFE filter to remove any insoluble matter. An amount of the clear solution was then diluted with Milli- $Q$ water, and the resulting mixture was subjected to analysis by high performance liquid chromatography (HPLC).

2.3. Analytical Methods. The composition of the reaction mixture was determined by HPLC. The HPLC device consists of an Agilent 1200 pump, a Bio-Rad organic acid column (Aminex HPX-87H), a Waters 410 differential refractive index detector, and a UV detector. The mobile phase was $5 \mathrm{mM}$ aqueous sulfuric acid at a flow rate of $0.55 \mathrm{~mL} \mathrm{~min}^{-1}$. The HPLC column was operated at $60{ }^{\circ} \mathrm{C}$. The concentration of compounds in the product mixture was determined using 
calibration curves obtained by analyzing standard solutions with known concentrations. A typical HPLC chromatogram of a sample is shown in Figure 2.

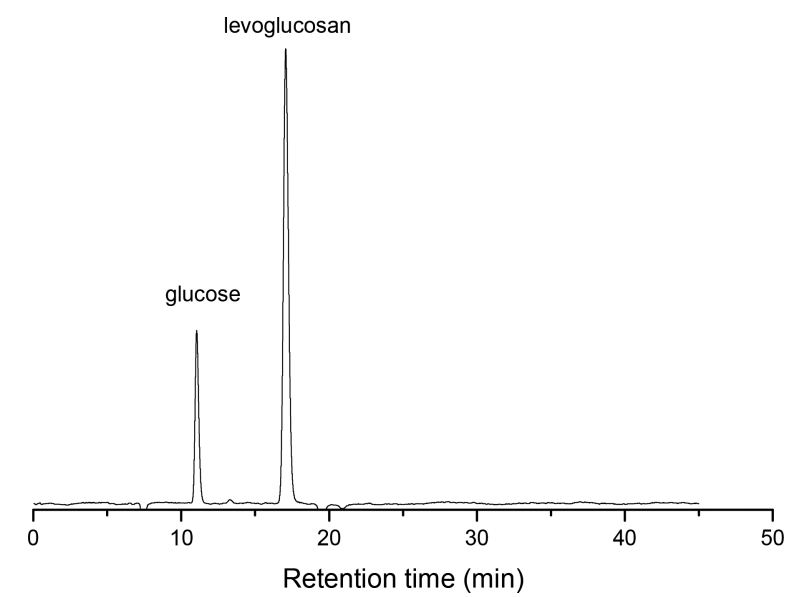

Figure 2. Typical HPLC chromatogram for a product mixture of LG hydrolysis in water.

2.4. Definitions and Determination of the Kinetic Parameters. The concentrations of the relevant compounds as measured by HPLC were used to calculate the conversion of LG $\left(X_{\mathrm{LG}}\right)$ and the yield of GLC $\left(Y_{\mathrm{GLC}}\right)$. The conversion and yield definitions are given in eqs 1 and 2 .

$$
\begin{aligned}
X_{\mathrm{LG}} & =\frac{\left(C_{\mathrm{LG}, 0}-C_{\mathrm{LG}}\right)}{C_{\mathrm{LG}, 0}} \\
Y_{\mathrm{GLC}} & =\frac{\left(C_{\mathrm{GLC}}\right)}{C_{\mathrm{LG}, 0}}
\end{aligned}
$$

The kinetic parameters of the reaction were obtained using the MATLAB R2016a software package. A maximum-likelihood approach, which is based on the minimization of errors between the experimental data and kinetic model (consisting of a number of differential equations and corresponding initial conditions), was applied. Details on this procedure are given in the literature. ${ }^{32,33}$ The lsqnonlin method was used to solve the nonlinear square problems to minimize the error between the measured values and the model.

\section{RESULTS AND DISCUSSION}

3.1. Product Distribution Using Sulfuric Acid As the Catalyst. A total of 38 experimental series were conducted in a broad range of reaction conditions $\left(80-160{ }^{\circ} \mathrm{C}, C_{\mathrm{LG}, 0}=0.1-1\right.$ $\mathrm{M})$ using sulfuric acid as the catalyst $(0.05-0.5 \mathrm{M})$. A typical example of a reaction profile $\left(160{ }^{\circ} \mathrm{C}, \mathrm{C}_{\mathrm{LG}, 0}=1 \mathrm{M}, \mathrm{C}_{\mathrm{H}_{2} \mathrm{SO}_{4}}=0.1\right.$ $\mathrm{M})$ is given in Figure $3 \mathrm{a}$. At these conditions, $\mathrm{LG}$ is converted within $10 \mathrm{~min}$ to GLC. At prolonged reaction times, the concentration of GLC is reduced, and HMF, levulinic acid (LA), and formic acid (FA) are formed. These are known products from the subsequent dehydration reactions of GLC in acidic conditions. ${ }^{31}$ In addition, the color of the solution changes from colorless to light yellow and finally to brown with the concomitant formation of solids, indicative for the formation of humins. These are known to consist of oligomeric-polymeric condensed structures and are inevitably formed upon the treatment of GLC in acidic conditions at elevated temperatures. ${ }^{31}$

Mass balance calculations were performed based on the total amount of HPLC detectable (LG, GLC, HMF, LA, FA), and the LG intake and the results are given in Figure $3 \mathrm{~b}$. It is evident that particularly in the initial stage of the reaction, mass balance closure is not quantitative, meaning that small amounts of other components are formed. This is also clear when considering the profile after about $10 \mathrm{~min}$, showing quantitative LG conversion, whereas the amount of GLC is at maximum about $85 \%$ of the initial LG concentration. Indeed, some unknown components are visible at the initial stage of the reaction in the HPLC chromatograms. A possibility is the formation of dihydroxyacetone (DHA), ${ }^{34}$ a known degradation product of LG at acidic conditions; however, its formation could not be confirmed unequivocally. These findings are of interest for the development of the kinetic models as they imply the existence of a parallel pathway for LG hydrolysis not leading to GLC but to unknown components.

To test the reproducibility of the experiments, 10 randomly selected experimental series (from 38 batch experiments in total) were performed twice, and the result of a representative set of experiments is given in Figure 4. It implies that the reproducibility of the experiments is good.

3.2. Effect of Process Variables on the Hydrolysis Rate of LG. The effect of temperature on the conversion of LG is given in Figure 5 and shows that the temperature has a major

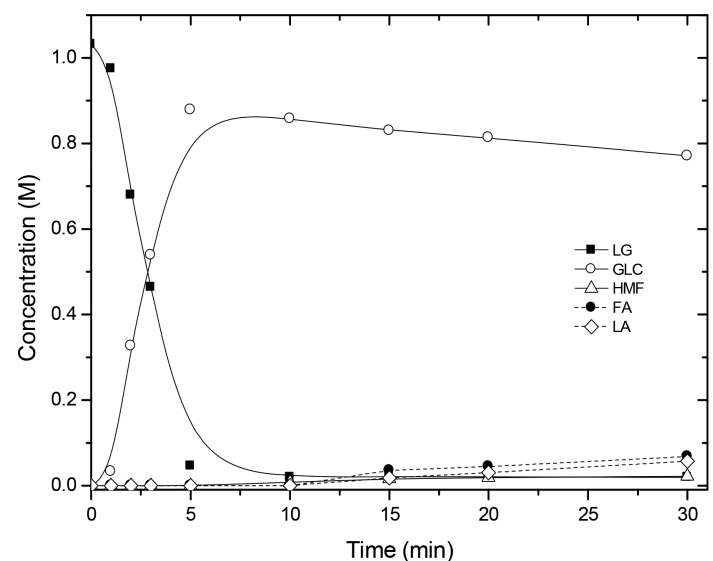

(a)

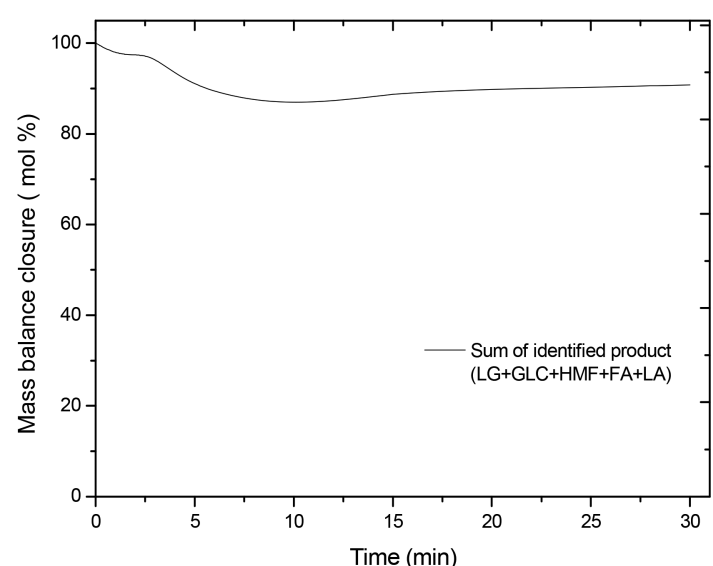

(b)

Figure 3. Representative example of a concentration profile (left) and the mass balance closure (right) at $160{ }^{\circ} \mathrm{C}, \mathrm{C}_{\mathrm{LG}, 0}=1 \mathrm{M}$ and $\mathrm{C}_{\mathrm{H}_{2} \mathrm{SO}_{4}}=0.1 \mathrm{M}$. 


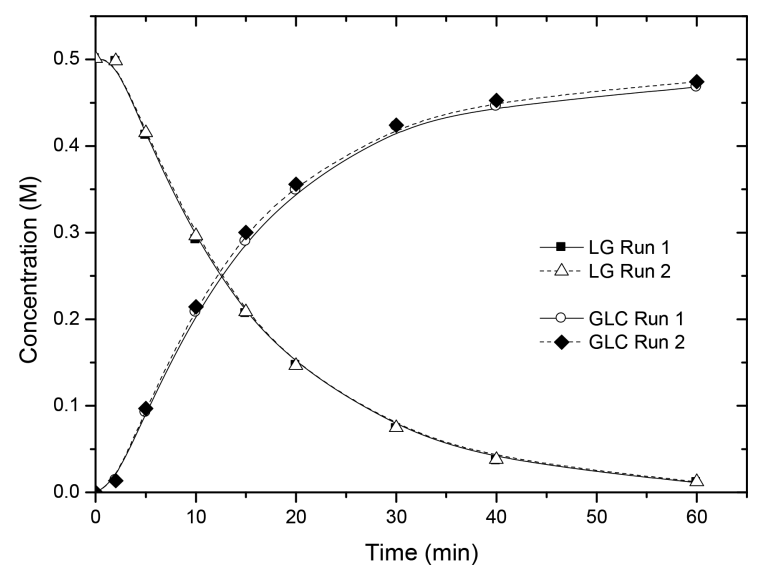

Figure 4. Reproducibility experiment for the acid-catalyzed conversion of $\mathrm{LG}\left(120{ }^{\circ} \mathrm{C} \mathrm{C}_{\mathrm{LG}, 0}=0.5 \mathrm{M}, \mathrm{C}_{\mathrm{H}_{2} \mathrm{SO}_{4}}=0.1 \mathrm{M}\right)$.

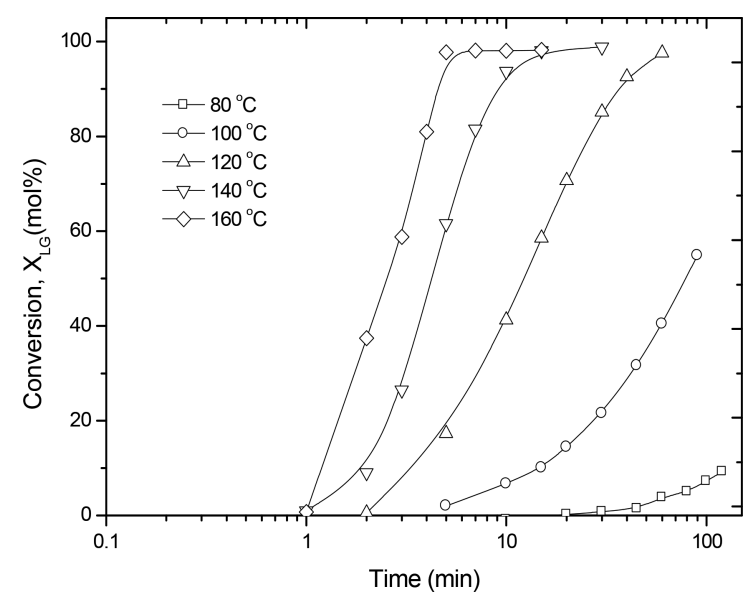

Figure 5. Effect of temperature on the conversion of $\mathrm{LG}\left(C_{\mathrm{LG}, 0}=0.5\right.$ $\left.\mathrm{M}, \mathrm{C}_{\mathrm{H}_{2} \mathrm{SO}_{4}}=0.1 \mathrm{M}\right)$.

effect. For example, at a temperature of $140{ }^{\circ} \mathrm{C}, 94 \mathrm{~mol} \%$ of LG conversion $\left(X_{\mathrm{LG}}\right)$ was obtained after $10 \mathrm{~min}$, whereas quantitative conversion is not attainable within $100 \mathrm{~min}$ batch time when the temperature is below $120{ }^{\circ} \mathrm{C}$.

In Figure 6a the effect of the catalyst concentration $\left(\mathrm{C}_{\mathrm{H}_{2} \mathrm{SO}_{4}}\right)$ on LG conversion versus time $\left(140{ }^{\circ} \mathrm{C}\right.$ and $\left.C_{\mathrm{LG}, 0}=0.5 \mathrm{M}\right)$ is given. The reaction is evidently enhanced at higher acid concentrations, and higher conversions at lower batch times are attained at higher catalyst concentrations. The GLC yields are also a function of the acid concentration. However, this effect is only pronounced at high conversions and acid concentrations, see Figure $6 \mathrm{~b}$ for details. Apparently, at these extremes, the consecutive reaction of GLC to HMF and LA takes place to a significant extent.

The effect of the initial concentrations of LG was investigated $\left(C_{\mathrm{LG}, 0}=0.1-1 \mathrm{M}, 120{ }^{\circ} \mathrm{C}\right.$ and $C_{\mathrm{H}_{2} \mathrm{SO}_{4}}=0.05$ $\mathrm{M})$, and the conversion of LG was found to be independent of the initial loading concentration of LG (Figure 7a). This is a strong indication that LG hydrolysis is first order in LG. Moreover, the initial concentration of LG has a small though significant influence on the GLC yield (Figure $7 \mathrm{~b}$ ). At higher LG loading, the yield of GLC is slightly reduced at prolonged batch times. This might be due to a higher rate of formation of soluble and insoluble polymers at higher LG concentrations, resulting in a decrease in the yield of GLC.

3.3. Kinetic Model Development for Sulfuric Acid. A kinetic model for the reaction of LG in water with sulfuric acid as the catalyst was developed involving a sequence of reactions based on the products formed (Scheme 1). It initially involves two parallel reactions for $\mathrm{LG}$, viz. the main hydrolysis reaction to GLC and a lumped reaction to other products (P1). This lumped reaction has to be considered based on mass balance consideration (Figure 3), particularly at high temperatures. In addition, glucose is assumed to react further to among others HMF, LA, FA, and soluble and insoluble humins. The latter reactions are lumped into one overall reaction to products $\mathrm{P} 2$. Based on the experiments with variable LG intakes, it was shown that the reaction is about first order in LG, and this value was also used as the input in the kinetic model.

Using the first order reaction assumption, the reaction rates of the three individual reactions are defined in eqs $3-5$.

$$
\begin{aligned}
& R_{1 \mathrm{LG}}=k_{1 \mathrm{LG}}\left(C_{\mathrm{LG}}\right) \\
& R_{2 \mathrm{LG}}=k_{2 \mathrm{LG}}\left(C_{\mathrm{LG}}\right) \\
& R_{1 \mathrm{GLC}}=k_{1 \mathrm{GLC}}\left(C_{\mathrm{GLC}}\right)
\end{aligned}
$$

The temperature dependence of the kinetic constants was introduced by using modified Arrhenius equations (eqs 6-8)

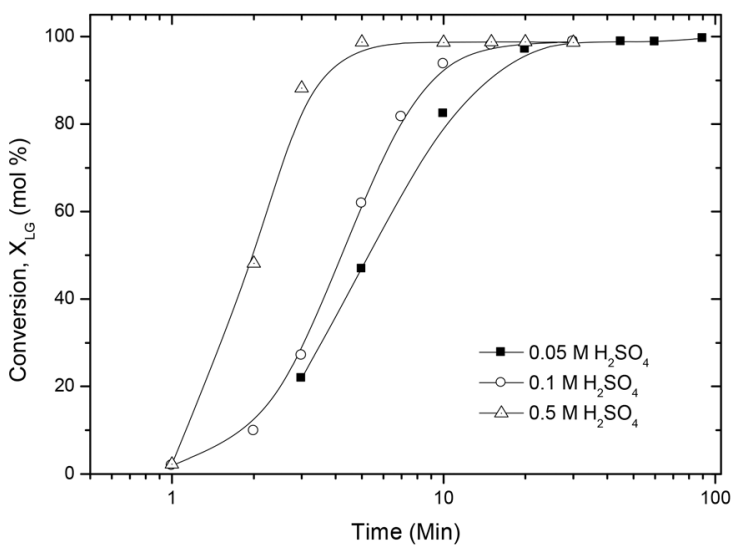

(a)

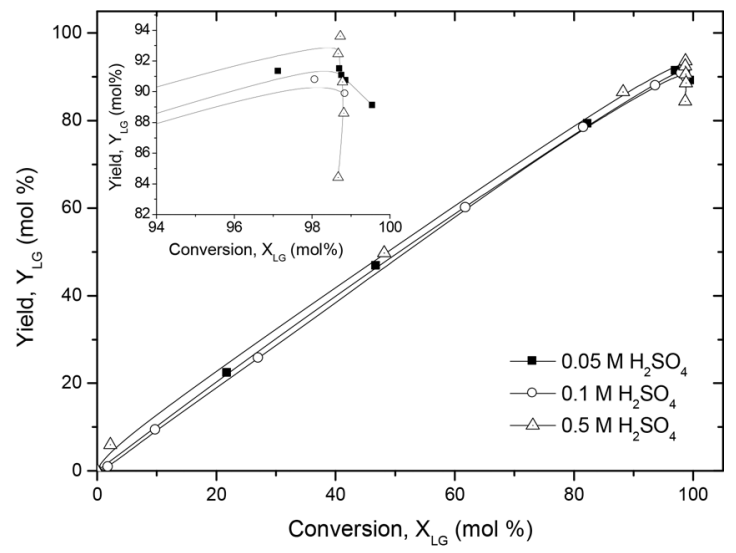

(b)

Figure 6. Effect of acid concentration on LG conversion, $X_{\mathrm{LG}}$ (a) and yield of GLC, $Y_{\mathrm{GLC}}$ (b). Reaction conditions: $140{ }^{\circ} \mathrm{C}$ and $C_{\mathrm{LG}, 0}=0.5 \mathrm{M}$. 


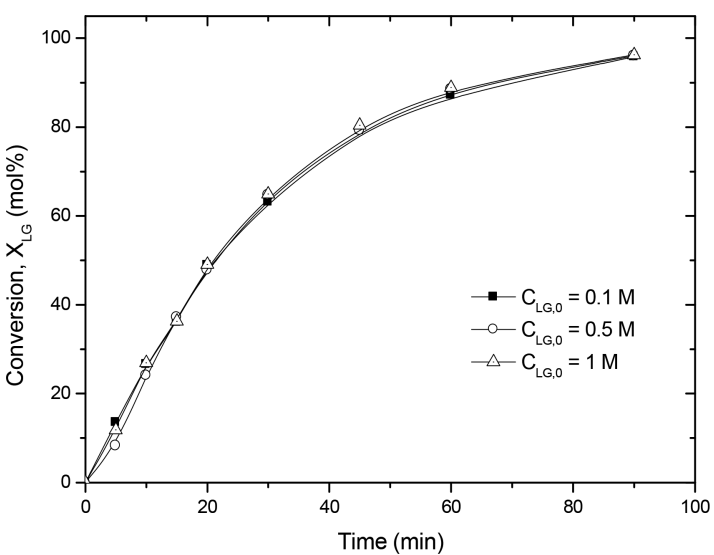

(a)

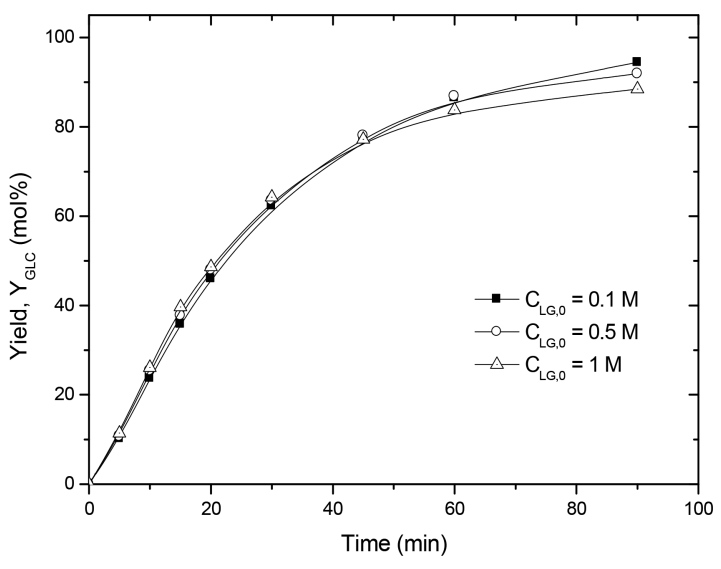

(b)

Figure 7. Effect of LG initial loading on its conversion, $X_{\mathrm{lg}}$ (a) and yield of GLC, $Y_{\mathrm{GLC}}$ (b) at reaction conditions: $120{ }^{\circ} \mathrm{C}, C_{\mathrm{H}_{2} \mathrm{SO}_{4}}=0.05 \mathrm{M}$.

Scheme 1. Proposed Scheme for LG Hydrolysis in Acidic Solutions

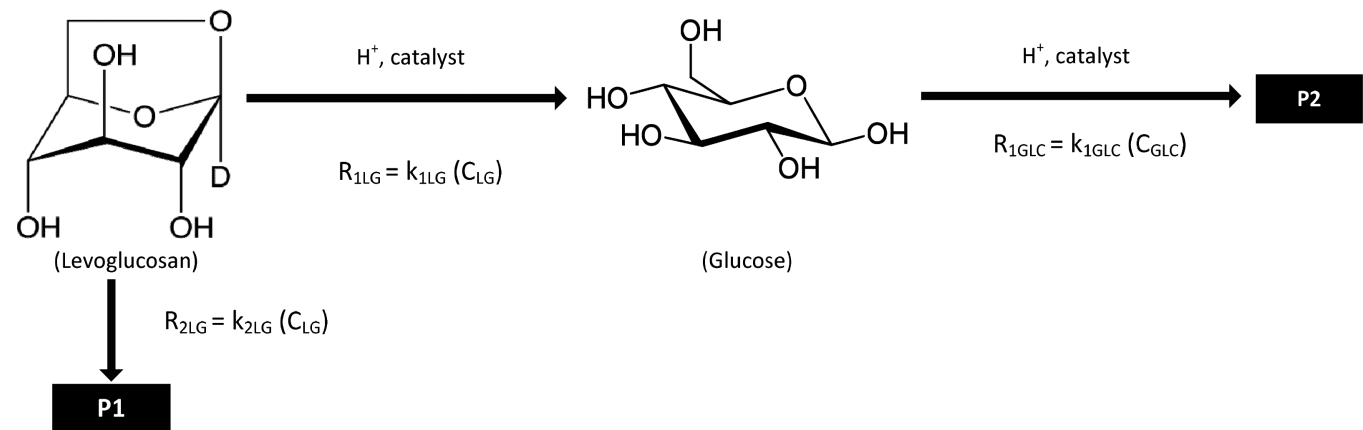

$$
\begin{aligned}
& k_{1 \mathrm{LG}}=\left(C_{\mathrm{H}^{+}}\right) k_{1 \mathrm{RLG}} \exp \left[\frac{E_{1 \mathrm{LG}}}{R}\left(\frac{T-T_{\mathrm{R}}}{T_{\mathrm{R}} T}\right)\right] \\
& k_{2 \mathrm{LG}}=\left(C_{\mathrm{H}^{+}}\right) k_{2 \mathrm{RLG}} \exp \left[\frac{\left.E_{2 \mathrm{LG}}\left(\frac{T-T_{\mathrm{R}}}{T_{\mathrm{R}} T}\right)\right]}{k_{1 \mathrm{GLC}}=\left(C_{\mathrm{H}^{+}}\right) k_{1 \mathrm{RGLC}} \exp \left[\frac{E_{1 \mathrm{GLC}}}{R}\left(\frac{T-T_{\mathrm{R}}}{T_{\mathrm{R}} T}\right)\right]}\right.
\end{aligned}
$$

where $T$ is a function of time (see the Supporting Information for more details), and $T_{R}$ is reference temperature $\left(115{ }^{\circ} \mathrm{C}\right)$. The order in acid is also assumed to be one, and this is incorporated in eqs $6-8$.

The reaction is assumed to be catalyzed by protons, of which the concentration was calculated using eq 9 .

$$
\begin{aligned}
C_{\mathrm{H}^{+}}= & C_{\mathrm{H}_{2} \mathrm{SO}_{4}}+\frac{1}{2}\left(-\left(K_{\mathrm{a}, \mathrm{HSO}_{4}^{-}}+C_{\mathrm{H}_{2} \mathrm{SO}_{4}}\right)\right. \\
& \left.+\sqrt{\left(K_{\mathrm{a}, \mathrm{HSO}_{4}^{-}}+C_{\mathrm{H}_{2} \mathrm{SO}_{4}}\right)^{2}+4\left(C_{\mathrm{H}_{2} \mathrm{SO}_{4}} K_{\mathrm{a}, \mathrm{HSO}_{4}}\right)}\right)
\end{aligned}
$$

The term $\mathrm{K}_{\mathrm{a}, \mathrm{HSO}_{4}}{ }^{-}$in eq 9 represents the dissociation constant of $\left(\mathrm{HSO}_{4}\right)^{-}$. This value is temperature dependent and given by eqs 10 and $11 .^{35}$

$$
\begin{aligned}
& \mathrm{pK}_{\mathrm{a}, \mathrm{HSO}_{4}^{-}}=0.0152 T-2.636 \\
& \mathrm{pK}_{\mathrm{a}, \mathrm{HSO}_{4}^{-}}=-\log _{10}\left(K_{\mathrm{a}, \mathrm{HSO}_{4}^{-}}\right)
\end{aligned}
$$

where $T$ is the temperature in $\mathrm{K}$.

In a batch system, the concentrations of LG and GLC versus time are represented by the differential equations given in eqs 12 and 13.

$$
\begin{gathered}
\frac{\mathrm{d} C_{\mathrm{LG}}}{\mathrm{d} t}=-\left(R_{1 \mathrm{LG}}+R_{2 \mathrm{LG}}\right) \\
\frac{\mathrm{d} C_{\mathrm{GLC}}}{\mathrm{d} t}=R_{1 \mathrm{LG}}-R_{1 \mathrm{GLC}}
\end{gathered}
$$

In total, 38 concentration-time profiles at different temperatures, acid concentration, and LG intake were determined experimentally, giving a total of 684 data points $(9$ samples per experiment, concentrations of LG, and GLC for each sample at certain reaction times). The best estimates of the kinetic parameters and their standard deviations, as determined by minimization of the errors between all experimental data and the kinetic model, are shown in Table 1.

Comparison of the experimental data and the output of the kinetic model demonstrates a good fit for a broad range of reaction conditions (Figure 8). A parity chart (Figure 9) shows the goodness-of-fit between the experimental and model data.

The activation energy obtained in this study $\left(123.4 \mathrm{~kJ} \mathrm{~mol}^{-1}\right)$ is comparable to the one found in the literature $\left(114 \mathrm{~kJ} \mathrm{~mol}^{-1}\right)$ using sulfuric acid catalyst at lower temperatures (50-130 $\left.{ }^{\circ} \mathrm{C}\right) .{ }^{9}$ However, it is considerably higher than the value of $97 \mathrm{~kJ}$ $\mathrm{mol}^{-1}$ found using hydrochloric acid at lower temperatures $\left(25-50{ }^{\circ} \mathrm{C}\right) .{ }^{29}$ Whether this is an intrinsic feature of $\mathrm{HCl}$ or due to the large difference in temperatures between ours and the $\mathrm{HCl}$ catalyzed study is not clear yet. 
Table 1. Kinetic Parameters for the Reactions of LG to Products with Sulfuric Acid as the Catalyst

\begin{tabular}{|c|c|c|c|}
\hline parameters & estimated value & unit & description \\
\hline$k_{1 \mathrm{RLG}}$ & $0.599 \pm 0.009$ & $\left(\mathrm{M}^{-1} \min ^{-1}\right)^{a}$ & $\begin{array}{l}\text { reaction rate constant of } \\
k_{\mathrm{lLG}} \text { at ref temp }\end{array}$ \\
\hline$E_{1 \mathrm{LG}}$ & $123.4 \pm 1.1$ & $\mathrm{~kJ} \mathrm{~mol}^{-1}$ & activation energy of $k_{1 \mathrm{LG}}$ \\
\hline$k_{2 \mathrm{RLG}}$ & $0.023 \pm 0.008$ & $\left(\mathrm{M}^{-1} \min ^{-1}\right)^{a}$ & $\begin{array}{l}\text { reaction rate constant of } \\
k_{2 \mathrm{LG}} \text { at ref temp }\end{array}$ \\
\hline$E_{2 \mathrm{LG}}$ & $166.5 \pm 14.9$ & $\mathrm{~kJ} \mathrm{~mol}^{-1}$ & activation energy of $k_{2 \mathrm{LG}}$ \\
\hline$k_{\text {IRGLC }}$ & $0.005 \pm 0.001$ & $\left(\mathrm{M}^{-1} \min ^{-1}\right)^{a}$ & $\begin{array}{l}\text { reaction rate constant of } \\
k_{1 \mathrm{GLC}} \text { at ref temp }\end{array}$ \\
\hline$E_{1 \mathrm{GLC}}$ & $97.2 \pm 9.9$ & $\mathrm{~kJ} \mathrm{~mol}^{-1}$ & activation energy of $k_{1 \mathrm{GLC}}$ \\
\hline$T$ & & & \\
\hline
\end{tabular}

3.4. Kinetic Model Development for Acetic Acid. A variety of acids have been identified in crude pyrolysis liquids. Examples are acetic acid, formic acid, glycolic acid, and propionic acid. ${ }^{10}$ Acetic acid is reported to be the major organic acid, and depending on the conditions applied during the pyrolysis process, its concentration can be up to $10 \mathrm{wt} \%{ }^{38}$ As such, it is also of interest to determine the effects of acetic acid on the rate of LG hydrolysis as this will also give insights in the rate of LG conversion in the pyrolysis process (e.g., the condenser systems) and during storage. This is of high importance when the objective of the pyrolysis process is to optimize LG concentrations and as such to reduce the rate of LG hydrolysis to GLC. In addition, this information will also be essential to determine possible anion effects on catalysis, i.e. whether acetate or sulfate anions play a role or that only the proton concentrations are determining the rate of the reactions.

The experimental procedure applied was similar to the experiments using sulfuric acid as the catalyst (see section 2.2),

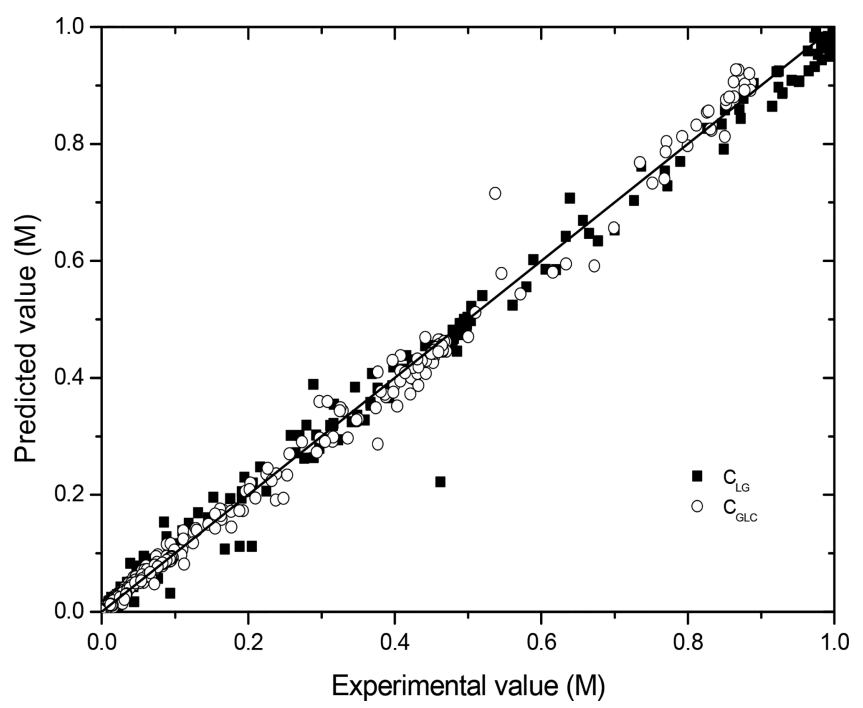

Figure 9. Parity plot for all experimental and model points with sulfuric acid as the catalyst.

with only slight differences in the experimental condition ranges $\left(C_{\mathrm{LG}, 0}=0.1-1 \mathrm{M}\right.$ at $T=160-200{ }^{\circ} \mathrm{C}$ and $C_{\mathrm{CH}_{3} \mathrm{COOH}}=$ 0.5-1 M). A total of 10 concentration versus time profiles were obtained each consisting of 16 data points representing the LG and GLC concentrations at certain reaction times. A higher temperature range was applied when compared to sulfuric acid to compensate for the by far lower proton concentration in solution when using acetic acid. At the end of the reactions, the reaction mixture was dark brown-black in color and contained significant amounts of solid (humin) byproducts.

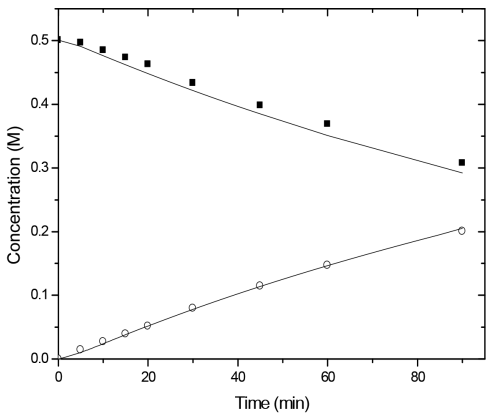

(a) $\mathrm{T}_{\text {oven }}=80^{\circ} \mathrm{C}$ and $\mathrm{C}_{\mathrm{H}_{2} \mathrm{SO}_{4}}=0.5 \mathrm{M}$

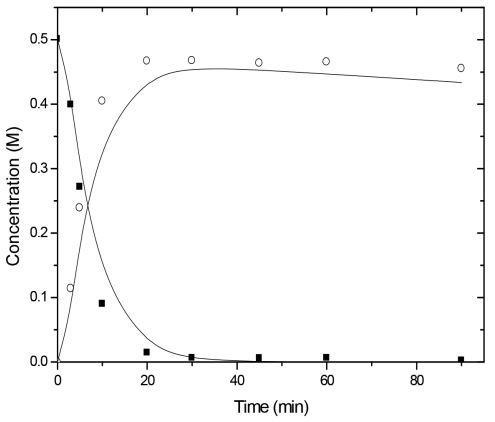

(d) $\mathrm{T}_{\text {oven }}=140{ }^{\circ} \mathrm{C}$ and $\mathrm{C}_{\mathrm{H}_{2} \mathrm{SO}_{4}}=0.05 \mathrm{M}$

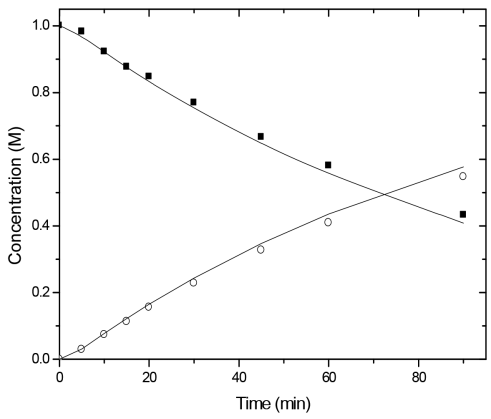

(b) $\mathrm{T}_{\text {oven }}=100{ }^{\circ} \mathrm{C}$ and $\mathrm{C}_{\mathrm{H}_{2} \mathrm{SO}_{4}}=0.1 \mathrm{M}$

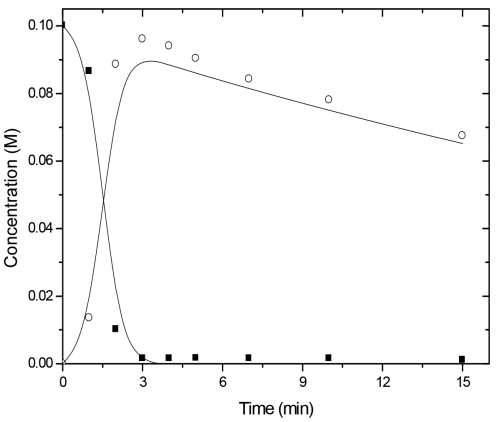

(e) $\mathrm{T}_{\text {oven }}=160{ }^{\circ} \mathrm{C}$ and $\mathrm{C}_{\mathrm{H}_{2} \mathrm{SO}_{4}}=0.5 \mathrm{M}$

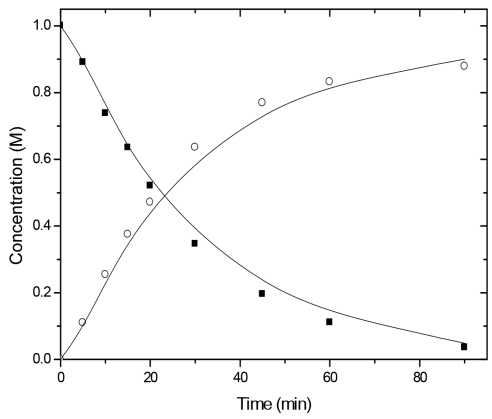

(c) $\mathrm{T}_{\text {oven }}=120{ }^{\circ} \mathrm{C}$ and $\mathrm{C}_{\mathrm{H}_{2} \mathrm{SO}_{4}}=0.05 \mathrm{M}$

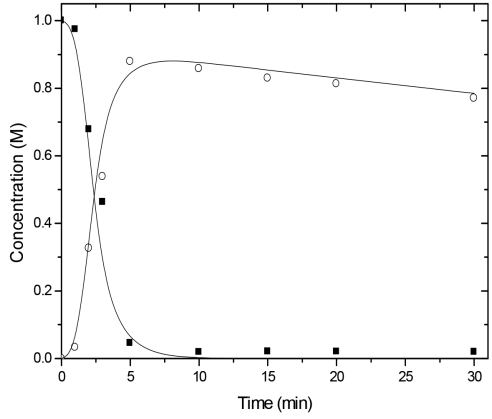

(f) $\mathrm{T}_{\text {oven }}=160^{\circ} \mathrm{C}$ and $\mathrm{C}_{\mathrm{H}_{2} \mathrm{SO}_{4}}=0.1 \mathrm{M}$

Figure 8. Comparison of experimental data $\left(\square: C_{\mathrm{LG}}\right.$ and $\left.\mathrm{O}: C_{\mathrm{GLC}}\right)$ and predicted data from the kinetic model (solid lines) for experiments with sulfuric acid as the catalyst. 
Typical concentration-time profiles for LG and the main product GLC at two temperatures $\left(160,180{ }^{\circ} \mathrm{C}\right)$ are provided in Figure 10 and show that the temperature has a large effect on

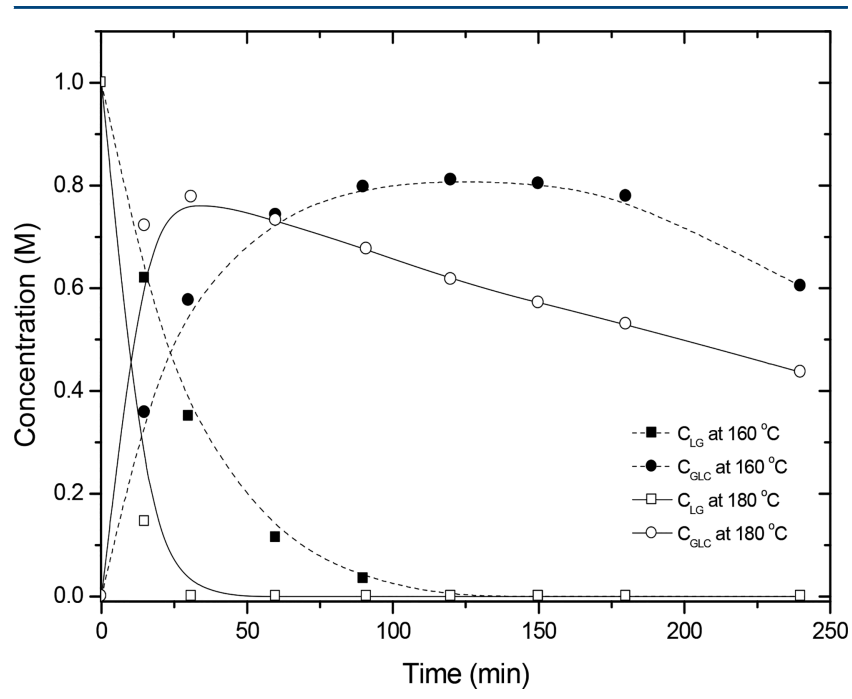

Figure 10. Typical concentration profiles for the reaction of $L G$ in an acetic acid-water system $\left(C_{\mathrm{LG}, 0}=1 \mathrm{M}, \mathrm{C}_{\mathrm{CH}_{3} \mathrm{COOH}}=0.5 \mathrm{M}, 160\right.$ and $\left.180{ }^{\circ} \mathrm{C}\right)$.

the LG conversion rates. However, the yields of GLC are lower than for sulfuric acid, indicating a higher rate for the degradation of GLC to among others soluble and insoluble (humins) byproducts. In line with the result from sulfuric acidcatalyzed experiments, GLC decomposition products were HMF, LA, and FA (results not shown for brevity). It is worth noting that the conversion rate of LG for acetic acid is significantly lower than for sulfuric acid (see Figure 3 for comparison).

Typically, the maximum yields of GLC are lower in acetic acid than in sulfuric acid, viz. $90 \mathrm{~mol} \%$ at $0.1 \mathrm{M} \mathrm{LG}$, an acetic acid concentration of $1 \mathrm{M}$, and a temperature of $160{ }^{\circ} \mathrm{C}$ compared to $98 \mathrm{~mol} \%$ at $0.1 \mathrm{M} \mathrm{LG}$, a sulfuric acid concentration of $0.1 \mathrm{M}$, and a temperature of $140{ }^{\circ} \mathrm{C}$. As such, the parallel decomposition of LG to other products than GLC seems to occur with a higher rate for acetic acid.

The kinetic model development for acetic acid is based on the reaction network given in Scheme 1. Eqs 3-8 and eqs 12 and 13 were applied to express the rate, kinetic rate constants, and concentrations of LG and GLC as a function of time, respectively. The concentration of $\mathrm{H}^{+}$was calculated using the acid dissociation constant (eq 14), which was corrected for the temperature by using eqs 15 and 16

$$
\begin{aligned}
& \mathrm{C}_{\mathrm{H}^{+}}=\frac{1}{2}\left(-\mathrm{K}_{\mathrm{a}, \mathrm{CH}_{3} \mathrm{COO}^{-}}\right.
\end{aligned}
$$

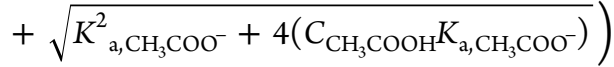

$$
\begin{aligned}
& \Delta G=-R T \ln K_{\mathrm{a}, \mathrm{CH}_{3} \mathrm{COO}^{-}} \approx 2.303 R T \mathrm{p} K_{\mathrm{a}, \mathrm{CH}_{3} \mathrm{COO}^{-}} \\
& \Delta G=\Delta H-T \Delta S
\end{aligned}
$$

where $R$ is the universal gas constant, $T$ is the temperature, and the values of $\Delta H$ and $\Delta S$ for acetic acid in water are reported to be $-0.41 \mathrm{~kJ} \mathrm{~mol}^{-1}$ and $-0.0925 \mathrm{~kJ} \mathrm{~mol}^{-1} \mathrm{~K}^{-1}$, respectively. ${ }^{36}$
The kinetic parameters were determined using MATLAB optimization routines, and the best estimations including their standard deviations are given in Table 2.

Table 2. Kinetic Parameters for LG Hydrolysis Acetic Acid

\begin{tabular}{|c|c|c|c|}
\hline parameters & estimated value & unit & description \\
\hline$k_{1 \mathrm{RLG}}$ & $0.610 \pm 0.063$ & $\left(\mathrm{M}^{-1} \min ^{-1}\right)^{a}$ & $\begin{array}{l}\text { reaction rate constant of } \\
k_{1 \mathrm{LG}} \text { at ref temp }\end{array}$ \\
\hline$E_{1 \mathrm{LG}}$ & $120.9 \pm 3.7$ & $\mathrm{~kJ} \mathrm{~mol}^{-1}$ & activation energy of $k_{1 \mathrm{LG}}$ \\
\hline$k_{2 \mathrm{RLG}}$ & $0.01 \pm 0.006$ & $\left(\mathrm{M}^{-1} \min ^{-1}\right)^{a}$ & $\begin{array}{l}\text { reaction rate constant of } \\
k_{2 \mathrm{LG}} \text { at ref temp }\end{array}$ \\
\hline$E_{2 \mathrm{LG}}$ & $189.0 \pm 18.0$ & $\mathrm{~kJ} \mathrm{~mol}{ }^{-1}$ & activation energy of $k_{2 \mathrm{LG}}$ \\
\hline$k_{\text {lRGLC }}$ & $0.116 \pm 0.028$ & $\left(\mathrm{M}^{-1} \min ^{-1}\right)^{a}$ & $\begin{array}{l}\text { reaction rate constant of } \\
k_{1 \mathrm{GLC}} \text { at ref temp }\end{array}$ \\
\hline$E_{1 \mathrm{GLC}}$ & $60.9 \pm 7.2$ & $\mathrm{~kJ} \mathrm{~mol}{ }^{-1}$ & activation energy of $k_{1 \mathrm{GLC}}$ \\
\hline${ }^{a_{\mathrm{T}}} \mathrm{T}_{\mathrm{R}}=115$ & & & \\
\hline
\end{tabular}
as the Catalyst

A good fit between experimental data and the kinetic model was observed, see Figure 11 for details. This is confirmed by the parity plot between experimental and modeled data (Figure 12).

\section{APPLICATION OF THE KINETIC MODELS}

4.1. Comparison between Acetic and Sulfuric Acid. With the kinetic models for both acid catalysts available, it is possible to gain insight into LG conversion, selectivity, and yield of GLC as a function of the type of acid catalyst and process conditions. For instance, a simulation of the typical batch time needed to achieve $90 \mathrm{~mol} \%$ LG conversion using sulfuric acid and acetic acid as catalysts at various temperatures is given in Figure 13.

Thus, it is clear that sulfuric acid is by far more reactive at similar acid concentrations than acetic acid, and the batch times required for $90 \%$ conversion at various temperatures are typically about 200 times lower.

4.2. Selectivity. Quantitative information on the effect of reaction conditions on the selectivity of the reaction can be obtained from the kinetic model. For this purpose, a rate selectivity parameter $(S)$ is used, which is defined as the ratio between the rate of the desired reactions and the rate of undesired reactions (eq 17). As such, $S$ considers the conversion of LG to GLC and to byproducts, without considering subsequent reactions of GLC. As such, this approach is only valid at relatively short batch times.

$$
S=\frac{(\text { rate of glucose formation) }}{\text { (rate of levoglucosan to decomposition product) }}=\frac{R_{1 \mathrm{LG}}}{R_{2 \mathrm{LG}}}
$$

Substitution of the rate expressions and kinetic constants equations as given in eq 6 and 7 leads to eq 18 .

$$
S=\frac{k_{1 \mathrm{RLG}}}{k_{2 \mathrm{RLG}}} \exp \left[\frac{\left(E_{1 \mathrm{LG}}-E_{2 \mathrm{LG}}\right)}{R}\left(\frac{T-T_{\mathrm{R}}}{T_{\mathrm{R}} T}\right)\right]
$$

The latter equation shows that the value of $S$ is independent of the $C_{\mathrm{LG}}$ and $\mathrm{C}_{\mathrm{H}_{2} \mathrm{SO}_{4}}$ or $\mathrm{C}_{\mathrm{CH}_{3} \mathrm{COOH}}$ and only a function of the temperature. The activation energies of the main reaction, $E_{1 \mathrm{LG}}$ $=123.4$ (for sulfuric acid) and $120.9 \mathrm{~kJ} \mathrm{~mol}^{-1}$ (for acetic acid), are lower than the side reaction, $E_{2 \mathrm{LG}}=166.5$ (for sulfuric acid) and $189 \mathrm{~kJ} \mathrm{~mol}^{-1}$ (for acetic acid, see Tables 1 and 2). Hence, to achieve high selectivity in the initial stage of the reaction, it is 


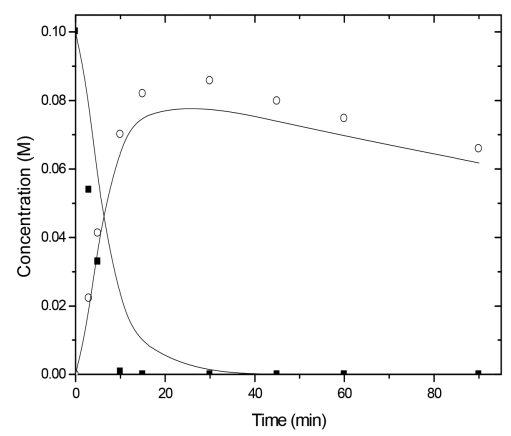

(a) $\mathrm{T}_{\text {oven }}=180^{\circ} \mathrm{C}$ and $\mathrm{C}_{\mathrm{CH}_{3} \mathrm{COOH}}=0.5 \mathrm{M}$

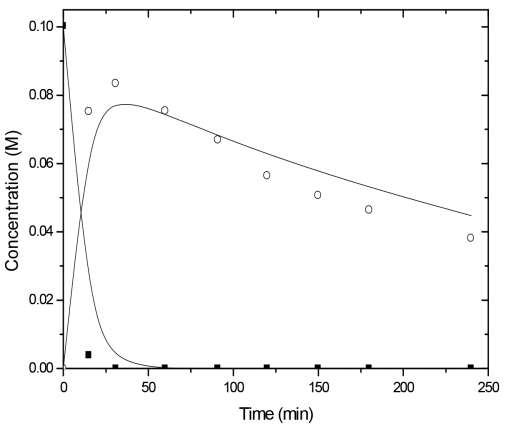

(d) $\mathrm{T}_{\text {oven }}=180^{\circ} \mathrm{C}$ and $\mathrm{C}_{\mathrm{CH}_{3} \mathrm{COOH}}=1 \mathrm{M}$

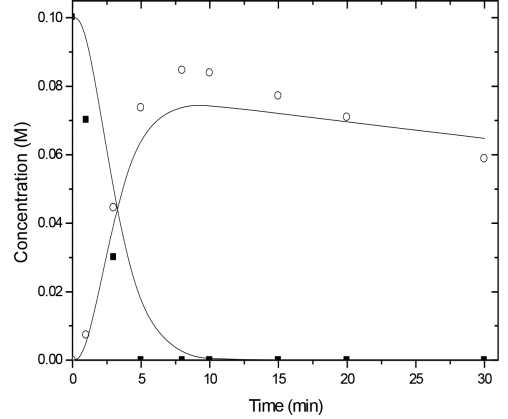

(b) $\mathrm{T}_{\text {oven }}=160{ }^{\circ} \mathrm{C}$ and $\mathrm{C}_{\mathrm{CH}_{3} \mathrm{COOH}}=0.5 \mathrm{M}$

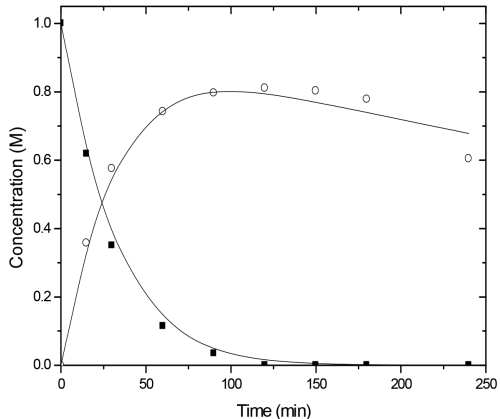

(e) $\mathrm{T}_{\text {oven }}=200{ }^{\circ} \mathrm{C}$ and $\mathrm{C}_{\mathrm{CH}_{3} \mathrm{COOH}}=1 \mathrm{M}$

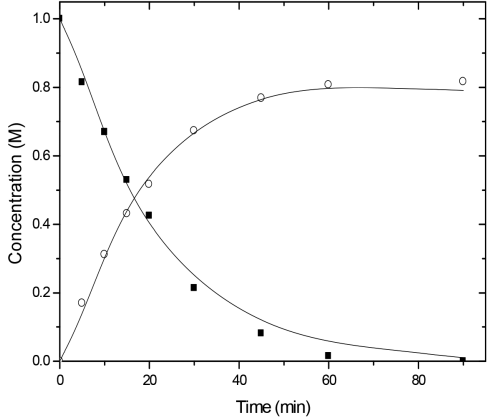

(c) $\mathrm{T}_{\text {oven }}=160{ }^{\circ} \mathrm{C}$ and $\mathrm{C}_{\mathrm{CH}_{3} \mathrm{COOH}}=1 \mathrm{M}$

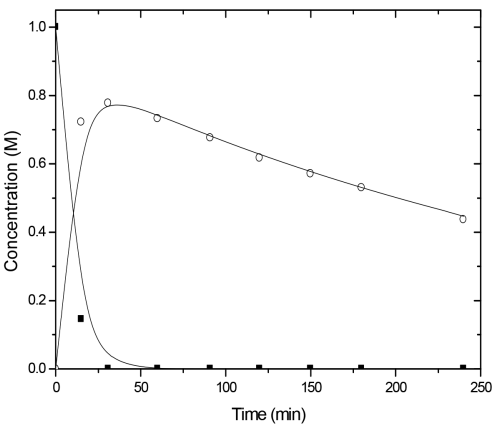

(f) $\mathrm{T}_{\text {oven }}=160^{\circ} \mathrm{C}$ and $\mathrm{C}_{\mathrm{CH}_{3} \mathrm{COOH}}=1 \mathrm{M}$

Figure 11. Comparison of experimental data acetic acid as the catalyst.

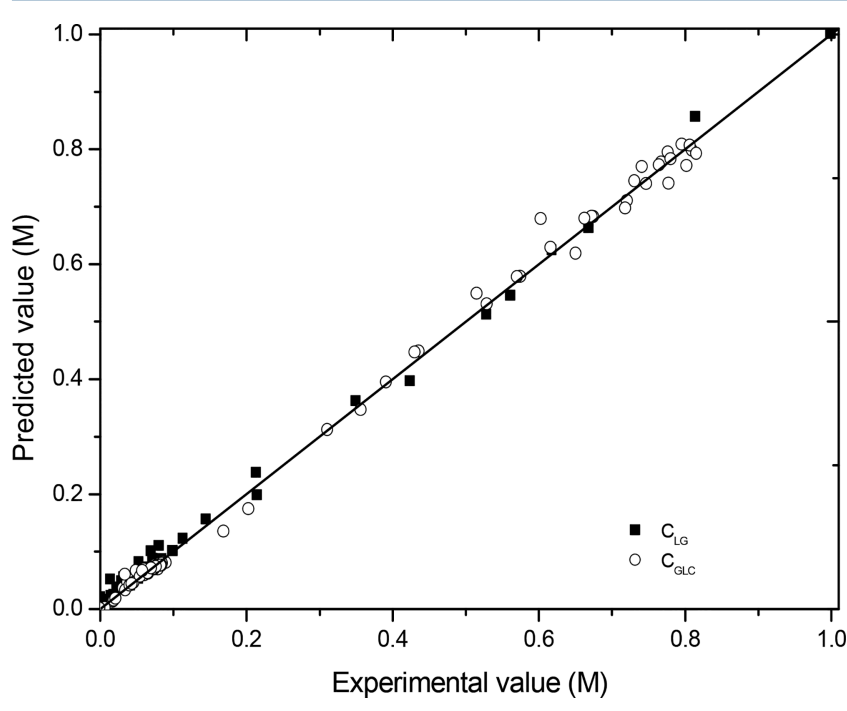

Figure 12. Parity plot for all experimental and model point with acetic acid as the catalyst.

best to perform the reaction at the lower temperatures. However, this goes at the expense of reaction rates and thus the space time yields. Therefore, a compromise between a high reaction rate, for which higher temperatures are preferred, and a good GLC selectivity, which is favored at lower temperatures, is required.

It is also of interest to compare the activation energies for the lumped decomposition reaction of GLC to P2 for both acids. The activation energy for acetic acid is $60.9 \pm 7.2 \mathrm{~kJ} \mathrm{~mol}^{-1}$, which is significantly lower than for sulfuric acid $(97.2 \pm 9.9 \mathrm{~kJ}$ $\mathrm{mol}^{-1}$ ). In line with this finding is the formation of significantly

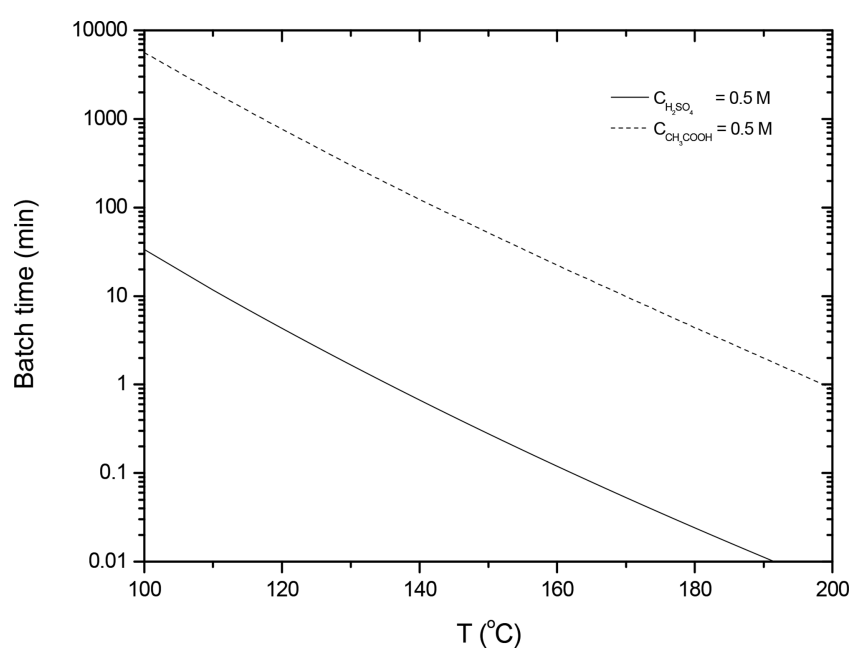

Figure 13. Required batch time for $X_{\mathrm{GLC}}=90 \mathrm{~mol} \%$ as a function of $T$ and type of acid $\left(C_{\mathrm{LG}, 0}=0.1 \mathrm{M}\right)$.

higher amounts of insoluble humins during the reaction with acetic acid. These observations are in agreement with a previous study by Girisuta et al. ${ }^{31}$ where various Bronsted acids $\left(\mathrm{H}_{3} \mathrm{PO}_{4}\right.$, oxalic acid, $\mathrm{HCl}, \mathrm{H}_{2} \mathrm{SO}_{4}$, and $\mathrm{HI}$ ) were tested as the catalyst for HMF conversion to LA. Here, the organic acid in the series (oxalic acid) gave a lower yield of LA and significantly higher amounts of humins than the mineral acids.

4.3. Determination of Optimum Reaction Conditions for Highest Yield. The kinetic model also allows determination of the optimum reaction condition to achieve the highest $Y_{\mathrm{GLC}}$. For this purpose, eq 1 is differentiated to give 


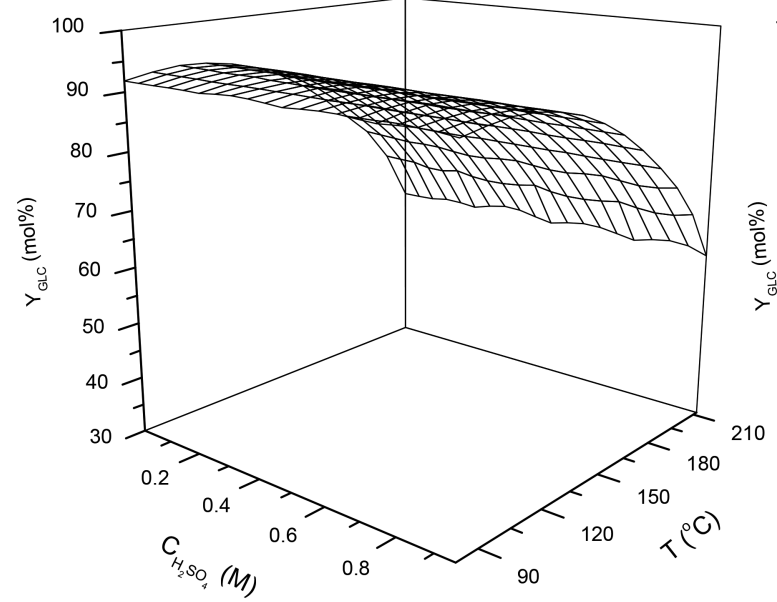

(a)

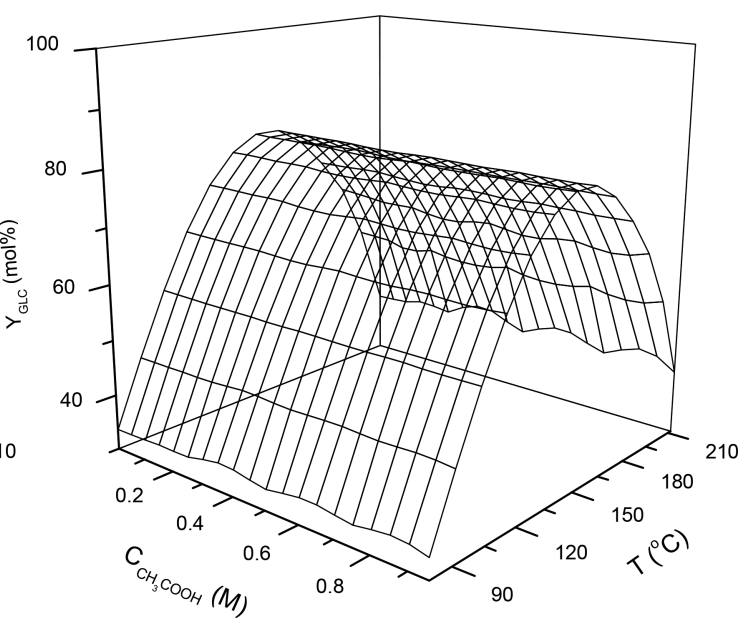

(b)

Figure 14. Effects of acid concentration and temperature on yield of GLC using sulfuric acid (a) and acetic acid (b) (at 0.1 M LG loading and 90 mol \% LG conversion).

$$
\mathrm{d} X_{\mathrm{LG}}=-\frac{\mathrm{d} C_{\mathrm{LG}}}{C_{\mathrm{LG}, 0}}
$$

The combination of eqs 12 and 13 and eq 19 leads to eq 20.

$$
\frac{\mathrm{d} C_{\mathrm{GLC}}}{\mathrm{d} X_{\mathrm{LG}}}=\frac{R_{1 \mathrm{LG}}-R_{1 \mathrm{GLC}}}{R_{1 \mathrm{LG}}+R_{2 \mathrm{LG}}} C_{\mathrm{LG}, 0}
$$

Eq 20 was solved from 0 to $90 \mathrm{~mol} \%$ LG conversion for the reactions using sulfuric acid and acetic acid as the catalyst. The GLC yield is subsequently calculated using eq 2 . Figure 14 shows the GLC yield as a function of temperature and acid concentration at an initial LG concentration of $0.1 \mathrm{M}$ and a $X_{\mathrm{LG}}$ of $90 \mathrm{~mol} \%$. Within this range of process conditions, the yield of GLC is almost independent of the acid concentration for both sulfuric and acetic acid. Also, it is evident that the GLC yield is highest at the lowest temperatures in the range for sulfuric acid (Figure 14a), while it is highest at intermediate temperatures for acetic acid (Figure 14b). This simulation is in line with the experimental results (vide supra).

\section{CONCLUSIONS}

A comprehensive experimental and modeling study on the acidcatalyzed reaction of LG to GLC in a batch reactor has been performed. A broad range of reaction conditions was tested, including variation in initial LG intake $(0.1-1 \mathrm{M})$, temperature $\left(80-200{ }^{\circ} \mathrm{C}\right.$ ), and acid catalysts (sulfuric acid, $0.05-0.5 \mathrm{M}$ and acetic acid, $0.5-1 \mathrm{M})$. In the temperature range used in this study, sulfuric acid gave the highest GLC yield (max. 98 mol $\%)$, while the use of acetic acid as catalyst gave a lower yield (max. $90 \mathrm{~mol} \%$ ) due to byproduct formation.

Furthermore, a broadly applicable kinetic model for the acidcatalyzed LG decomposition for both the sulfuric and acetic acid catalysts has been developed, assuming first order dependencies in substrates and acid. A maximum-likelihood approach has been applied to estimate the kinetic parameters, and a good fit between experimental data and modeling results was obtained. The model implies that the GLC yield is essentially independent of the LG loading. Within the investigated range of reaction conditions, the GLC yield is at the highest when the reaction temperature is between 100 and
$120{ }^{\circ} \mathrm{C}$ (with sulfuric acid) and between 140 and $160{ }^{\circ} \mathrm{C}$ (with acetic acid).

\section{ASSOCIATED CONTENT}

Supporting Information

The Supporting Information is available free of charge on the ACS Publications website at DOI: 10.1021/acs.iecr.8b00013.

Calculation of the temperature-time profile in the small scale batch reactors and an overview of experimental data (PDF)

\section{AUTHOR INFORMATION}

\section{Corresponding Author}

*E-mail: h.j.heeres@rug.nl.

ORCID $\odot$

H. J. Heeres: 0000-0002-1249-543X

Notes

The authors declare no competing financial interest.

\section{ACKNOWLEDGMENTS}

R.M.A. would like to thank the Directorate General of Higher Education, Ministry of Education and Culture, Indonesia for funding of her Ph.D. program. The authors also thank Jan Henk Marsman, Leon Rohrbach, Erwin Wilbers, Marcel de Vries, and Anne Appeldoorn for analytical and technical support and Henk van de Bovenkamp for invaluable discussions about MATLAB programing.

\section{NOMENCLATURE}

$\Delta H=$ change in enthalpy $\left(\mathrm{kJ} \mathrm{mol}{ }^{-1}\right)$

$\Delta G=$ Gibbs free energy $\left(\mathrm{kJ} \mathrm{mol}^{-1}\right)$

$\Delta S=$ change in entropy $\left(\mathrm{kJ} \mathrm{mol}^{-1} \mathrm{~K}^{-1}\right)$

$A_{\mathrm{t}}=$ heat transfer area $\left(\mathrm{m}^{2}\right)$

$\mathrm{C}_{\mathrm{H}}{ }^{+}=$concentration of $\mathrm{H}^{+}(\mathrm{M})$

$C_{\mathrm{GLC}}=$ concentration of GLC $(\mathrm{M})$

$C_{\mathrm{GLC}, 0}=$ initial concentration of GLC (M)

$C_{\mathrm{LG}}=$ concentration of $\mathrm{LG}(\mathrm{M})$

$C_{\mathrm{LG}, 0}=$ initial concentration of LG (M)

$C_{p}=$ heat capacity of reaction mixture $\left(\mathrm{J} \mathrm{g}^{-1} \mathrm{~K}^{-1}\right)$ 
$E_{1 \mathrm{GLC}}=$ activation energy of the decomposition of GLC to P2 $\left(\mathrm{kJ} \mathrm{mol}^{-1}\right)$

$E_{1 \mathrm{LG}}=$ activation energy of the main reaction of LG to GLC $\left(\mathrm{kJ} \mathrm{mol}{ }^{-1}\right)$

$E_{2 \mathrm{LG}}=$ activation energy of the side reaction of LG to P1 (kJ $\mathrm{mol}^{-1}$ )

$h=$ lumped heat transfer term $\left(\mathrm{min}^{-1}\right)$

$k_{1 \mathrm{GLC}}=$ reaction rate constant of the decomposition of GLC $\left(\mathrm{M} \mathrm{min}^{-1}\right)$

$k_{1 \mathrm{LG}}=$ reaction rate constant of the main reaction of $\mathrm{LG}$ to $\operatorname{GLC}\left(\mathrm{M} \mathrm{min}^{-1}\right)$

$k_{1 \mathrm{RGLC}}=$ reaction rate constant $k_{1 \mathrm{GLC}}$ at reference temperature $\left(\mathrm{M} \mathrm{min}^{-1}\right)$

$k_{1 \mathrm{RLG}}=$ reaction rate constant $k_{1 \mathrm{LG}}$ at reference temperature $\left(\mathrm{M} \min ^{-1}\right)$

$k_{2 \mathrm{LG}}=$ reaction rate constant of LG for the side reaction to $\mathrm{X}$ $\left(\mathrm{M} \mathrm{min}^{-1}\right)$

$k_{2 \mathrm{RLG}}=$ reaction rate constant $k_{2 \mathrm{LG}}$ at reference temperature $\left(\mathrm{M} \min ^{-1}\right)$

$K_{\mathrm{a}}=$ acid dissociation constant $(-)$

$M=$ mass of the reaction mixture $(\mathrm{g})$

$R=$ universal gas constant, $8.3144 \mathrm{~J} \mathrm{~mol}^{-1} \mathrm{~K}^{-1}$

$R_{1 \mathrm{GLC}}=$ reaction rate of GLC P2 $\left(\mathrm{mol} \mathrm{L}^{-1} \mathrm{~min}^{-1}\right)$

$R_{1 L G}=$ reaction rate of LG to GLC $\left(\mathrm{mol} \mathrm{L}^{-1} \mathrm{~min}^{-1}\right)$

$R_{2 \mathrm{LG}}=$ reaction rate of $\mathrm{LG}$ to $\mathrm{P} 1\left(\mathrm{~mol} \mathrm{~L}{ }^{-1} \mathrm{~min}^{-1}\right)$

$S=$ rate selectivity parameter $(-)$

$t=$ time $(\mathrm{min})$

$T=$ reaction temperature $\left({ }^{\circ} \mathrm{C}\right)$

$T_{\mathrm{i}}=$ temperature of reaction mixture at $t=0\left({ }^{\circ} \mathrm{C}\right)$

$T_{\text {oven }}=$ temperature of oven $\left({ }^{\circ} \mathrm{C}\right)$

$T_{\mathrm{R}}=$ reference temperature $\left({ }^{\circ} \mathrm{C}\right)$

$U=$ overall heat transfer coefficient $\left(\mathrm{W} \mathrm{m}^{-2} \mathrm{~K}^{-1}\right)$

$X_{\mathrm{LG}}=$ conversion of $\mathrm{LG}(\mathrm{mol} \%)$

$Y_{\mathrm{GLC}}=$ yield of GLC (mol \%)

\section{REFERENCES}

(1) Huber, G. W.; Iborra, S.; Corma, A. Synthesis of transportation fuels from biomass: chemistry, catalysts, and engineering. Chem. Rev. 2006, 106, 4044-4098.

(2) Ragauskas, A. J.; Williams, C. K.; Davison, B. H.; Britovsek, G.; Cairney, J.; Eckert, C. A.; Frederick, W. J., Jr; Hallett, J. P.; Leak, D. J.; Liotta, C. L.; Mielenz, J. R.; Murphy, R.; Templer, R.; Tschaplinski, T. The path forward for biofuels and biomaterials. Science 2006, 311, 484-489.

(3) Lian, J.; Garcia-Perez, M.; Coates, R.; Wu, H.; Chen, S. Yeast fermentation of carboxylic acids obtained from pyrolytic aqueous phases for lipid production. Bioresour. Technol. 2012, 118, 177-186.

(4) Isikgor, F. H.; Becer, C. R. Lignocellulosic biomass: a sustainable platform for the production of bio-based chemicals and polymers. Polym. Chem. 2015, 6, 4497-4559.

(5) Bennett, N. M.; Helle, S. S.; Duff, S. J. Extraction and hydrolysis of levoglucosan from pyrolysis oil. Bioresour. Technol. 2009, 100, 6059-6063.

(6) Lian, J.; Chen, S.; Zhou, S.; Wang, Z.; O’Fallon, J.; Li, C.; GarciaPerez, M. Separation, hydrolysis and fermentation of pyrolytic sugars to produce ethanol and lipids. Bioresour. Technol. 2010, 101, 96889699.

(7) Mettler, M. S.; Paulsen, A. D.; Vlachos, D. G.; Dauenhauer, P. J. Pyrolytic conversion of cellulose to fuels: levoglucosan deoxygenation via elimination and cyclization within molten biomass. Energy Environ. Sci. 2012, 5, 7864-7868.

(8) Czernik, S.; Bridgwater, A. Overview of applications of biomass fast pyrolysis oil. Energy Fuels 2004, 18, 590-598.

(9) Helle, S.; Bennett, N. M.; Lau, K.; Matsui, J. H.; Duff, S. J. A kinetic model for production of glucose by hydrolysis of levoglucosan and cellobiosan from pyrolysis oil. Carbohydr. Res. 2007, 342, 23652370.

(10) Sipilä, K.; Kuoppala, E.; Fagernäs, L.; Oasmaa, A. Characterization of biomass-based flash pyrolysis oils. Biomass Bioenergy 1998, $14,103-113$.

(11) Oasmaa, A.; Czernik, S. Fuel oil quality of biomass pyrolysis oils state of the art for the end users. Energy Fuels 1999, 13, 914-921.

(12) Bridgwater, A.; Peacocke, G. Fast pyrolysis processes for biomass. Renewable Sustainable Energy Rev. 2000, 4, 1-73.

(13) AnonymousFast pyrolysis. http://www.btgworld.com/en/rtd/ technologies/fast-pyrolysis (accessed Feb 19, 2018).

(14) Hoekstra, E.; Kersten, S. R.; Tudos, A.; Meier, D.; Hogendoorn, K. J. Possibilities and pitfalls in analyzing (upgraded) pyrolysis oil by size exclusion chromatography (SEC). J. Anal. Appl. Pyrolysis 2011, 91, $76-88$.

(15) Anex, R. P.; Aden, A.; Kazi, F. K.; Fortman, J.; Swanson, R. M.; Wright, M. M.; Satrio, J. A.; Brown, R. C.; Daugaard, D. E.; Platon, A. Techno-economic comparison of biomass-to-transportation fuels via pyrolysis, gasification, and biochemical pathways. Fuel 2010, 89, S29S35.

(16) Carlson, T. R.; Tompsett, G. A.; Conner, W. C.; Huber, G. W. Aromatic production from catalytic fast pyrolysis of biomass-derived feedstocks. Top. Catal. 2009, 52, 241-252.

(17) Alonso, D. M.; Bond, J. Q.; Serrano-Ruiz, J. C.; Dumesic, J. A. Production of liquid hydrocarbon transportation fuels by oligomerization of biomass-derived C 9 alkenes. Green Chem. 2010, 12, 992-999.

(18) Digman, B.; Joo, H. S.; Kim, D. Recent progress in gasification/ pyrolysis technologies for biomass conversion to energy. Environ. Prog. Sustainable Energy 2009, 28, 47-51.

(19) Yang, B.; Wyman, C. E. Pretreatment: the key to unlocking lowcost cellulosic ethanol. Biofuels, Bioprod. Biorefin. 2008, 2, 26-40.

(20) Li, L.; Zhang, H. Preparing levoglucosan derived from waste material by pyrolysis. Energy Sources 2004, 26, 1053-1059.

(21) Kuzhiyil, N.; Dalluge, D.; Bai, X.; Kim, K. H.; Brown, R. C. Pyrolytic Sugars from Cellulosic Biomass. ChemSusChem 2012, 5, $2228-2236$.

(22) Bozell, J. J.; Petersen, G. R. Technology development for the production of biobased products from biorefinery carbohydrates-the US Department of Energy's “top 10" revisited. Green Chem. 2010, 12, 539-554.

(23) Oasmaa, A.; Kuoppala, E.; Ardiyanti, A.; Venderbosch, R.; Heeres, H. Characterization of hydrotreated fast pyrolysis liquids. Energy Fuels 2010, 24, 5264-5272.

(24) Rover, M. R.; Johnston, P. A.; Jin, T.; Smith, R. G.; Brown, R. C.; Jarboe, L. Production of clean pyrolytic sugars for fermentation. ChemSusChem 2014, 7, 1662-1668.

(25) Hassan, E. B.; Abou-Yousef, H.; Steele, P. Increasing the efficiency of fast pyrolysis process through sugar yield maximization and separation from aqueous fraction bio-oil. Fuel Process. Technol. 2013, 110, 65-72.

(26) Venderbosch, R.; Ardiyanti, A.; Wildschut, J.; Oasmaa, A.; Heeres, H. Stabilization of biomass-derived pyrolysis oils. J. Chem. Technol. Biotechnol. 2010, 85, 674-686.

(27) Wang, Y. Catalytic hydrotreatment of pyrolysis liquids and fractions: Catalyst Development and Process Studies, Groningen, 2017.

(28) Kloekhorst, A.; Wildschut, J.; Heeres, H. J. Catalytic hydrotreatment of pyrolytic lignins to give alkylphenolics and aromatics using a supported Ru catalyst. Catal. Sci. Technol. 2014, 4, 2367-2377.

(29) Vidrio, E. Study of the kinetics of the acid-catalyzed hydrolysis of levoglucosan. McNair Scholars J. 2004, 5, 90-103.

(30) Mahfud, F.; Van Geel, F.; Venderbosch, R.; Heeres, H. Acetic acid recovery from fast pyrolysis oil. An exploratory study on liquidliquid reactive extraction using aliphatic tertiary amines. Sep. Sci. Technol. 2008, 43, 3056-3074.

(31) Girisuta, B.; Janssen, L. P. B. M.; Heeres, H. J. Green chemicals: A kinetic study on the conversion of glucose to levulinic acid. Chem. Eng. Res. Des. 2006, 84, 339-349. 
(32) Bard, Y. Nonlinear parameter estimation; Academic Press: 1974; pp 61-71.

(33) Knightes, C. D.; Peters, C. A. Statistical analysis of nonlinear parameter estimation for Monod biodegradation kinetics using bivariate data. Biotechnol. Bioeng. 2000, 69, 160-170.

(34) Hu, X.; Wu, L.; Wang, Y.; Song, Y.; Mourant, D.; Gunawan, R.; Gholizadeh, M.; Li, C. Acid-catalyzed conversion of mono-and polysugars into platform chemicals: Effects of molecular structure of sugar substrate. Bioresour. Technol. 2013, 133, 469-474.

(35) Dickson, A. G.; Wesolowski, D. J.; Palmer, D. A.; Mesmer, R. E. Dissociation constant of bisulfate ion in aqueous sodium chloride solutions to 250. degree. C. J. Phys. Chem. 1990, 94, 7978-7985.

(36) Goldberg, R. N.; Kishore, N.; Lennen, R. M. Thermodynamic quantities for the ionization reactions of buffers. J. Phys. Chem. Ref. Data 2002, 31, 231-370. 